\title{
Rapid rates of sperm DNA damage after activation in tench (Tinca tinca: Teleostei, Cyprinidae) measured using a sperm chromatin dispersion test
}

\author{
Carmen López-Fernández, Matthew J G Gage ${ }^{1}$, Francisca Arroyo, Altea Gosálbez, Ana M Larrán², \\ José L Fernández ${ }^{3}$ and Jaime Gosálvez \\ Unidad de Genética, Departamento de Biología, Edificio de Biología, Universidad Autónoma de Madrid, C/Darwin \\ no 2, 28049 Madrid, Spain, ${ }^{1}$ School of Biological Sciences, University of East Anglia, Norwich NR47TJ, UK, ${ }^{2}$ Instituto \\ Tecnológico Agrario de Castilla y León, Ctra. Burgos Km 118, Finca Zamadueñas, 47071 Valladolid, Spain and \\ ${ }^{3}$ Complejo Hospitalario Universitario Juan Canalejo, As Xubias 84, 15006 A Coruña, Spain
}

Correspondence should be addressed to J Gosálvez; Email: jaime.gosalvez@uam.es

\begin{abstract}
Spermatozoal haplotypic DNA is prone to damage, leading to male fertility problems. So far, the assessment of sperm DNA breakage has been challenging because protamines render the nuclear chromatin highly compacted. Here, we report the application of a new test to quantify DNA fragmentation in spermatozoa of an externally fertilizing teleost fish. The sperm chromatin dispersion (SCD) test uses a species-specific lysing solution to generate controlled protein depletion that, followed by DNA-specific fluorescent labelling, allows an easy morphological discrimination between nuclei affected by DNA damage. Using tench (Tinca tinca) as our model, we first trialled the test against established, but more technically demanding, assays employing in situ nick translation (ISNT) and the comet assay. The SCD test showed high concordance with ISNT, comet assay measures and a chromatin-swelling test, confirming the application of this straightforward SCD technique to various aspects of reproductive biology. Second, we examined between-male variation in DNA damage, and measured changes through time following spermatozoal activation. Between-male variation in the basal levels of average DNA damage ranged from 0 to $20 \%$ of sperm showing damage, and all showed increases in DNA fragmentation through time (0-60 $\mathrm{min})$. The rates of DNA damage increase are the fastest so far recorded in sperm for a living organism, and may relate to the external fertilization mode. Our findings have relevance for broodstock selection and optimizing IVF protocols routinely used in modern aquaculture.

Reproduction (2009) 138 257-266
\end{abstract}

\section{Introduction}

The existence of DNA fragmentation in ejaculated spermatozoa is a well-recognized, but poorly understood, phenomenon (Evenson \& Wixon 2006, Gosálvez et al. 2006). Packaging of the DNA haplotype within sperm cells is under strong selection to be extremely tightly arranged in a (quasi) specific paracrystalline configuration (Braun 2001), and sperm DNA is highly condensed (Ward \& Coffey 1991). This tight structural packaging is prone to organizational breakdown through sperm DNA fragmentation (SDF; Marchesi \& Feng 2007). SDF occurs when male haplotypic DNA suffers single- or double-stranded breaks, disrupting haplotype DNA configuration and leading to compromised fertility (Morris et al. 2002). Although SDF assessment in ejaculated semen samples and its consequences in fertilization are recognized under certain conditions in a few mammals, there is a need to understand the nature and extent of this process in other taxa that have so far received less attention.

Fish that employ external fertilization tend to produce comparatively large numbers of relatively very small spermatozoa, and may therefore be under strong selection to condense haplotypic DNA into a very small package (Stockley et al. 1997). Moreover, spawning in externally fertilizing freshwater fish is often associated with the requirement for rapid fertilization dynamics (Hoysak \& Liley 2001, Yeates et al. 2007). This pressure for fast gamete association may occur because freshwater spawning is a significant osmotic challenge to sperm cells after activation (Morisawa et al. 1983, Alavi \& Cosson 2006), and could be an important influence on DNA structural integrity. We therefore hypothesize that SDF dynamics in this externally fertilizing fish may proceed in a 
manner not previously recorded in other vertebrates, because fish sperm DNA packaging may be under particularly strong selection to be condensed (Ward \& Coffey 1991, Stockley et al. 1997), and the external freshwater fertilization environment places osmotic stress upon sperm cell structure (Morisawa et al. 1983, Alavi \& Cosson 2006).

In general, the SDF value for each animal has been represented as a single value at the time of assessment, giving rise to a static view of this parameter. However, we have recently demonstrated that SDF is actually a highly dynamic process, usually increasing after ejaculation and prior to oocyte fertilization; this phenomenon is especially relevant when considering handling times within artificial reproductive techniques (Gosálvez et al. 2009a, 2009b, López-Fernández et al. 2008). Therefore, one of the aims of this study was to assess SDF in tench (Tinca tinca, Teleostei, Cyprinidae) in order to determine how the dynamics of SDF vary over time in a fish species with gametes adapted for external fertilization in freshwater. To this purpose, we assess SDF in tench using the sperm chromatin dispersion test (SCD, Fernández et al. 2003, Gosálvez et al. 2006). The method uses a species-specific lysing solution that allows controlled protein depletion under specific incubation in a gel matrix, followed by DNA-specific fluorescent labelling that reveals the level of DNA fragmentation once exposed after lysis. Based on the SCD test, a specific prototype assay for tench (Halomax Proto-Tinca) was produced, and then the ability to assess SDF was validated against a) direct DNA labelling using in situ polymerization of modified nucleotides by in situ nick translation (ISNT, Gorczyca et al. 1993) that specifically measures DNA nicks and breaks, and b) the comet assay using neutral and alkaline buffers for determining single- or double-stranded DNA breaks (Tice et al. 2000).

In addition to generating pure biological understanding of SDF in a new taxon with different adaptations to external fertilization, there are good applied reasons to test SDF in fish. IVF techniques for assisted reproduction are important in a number of fish species with either commercial or conservation relevance (e.g. cryopreservation and IVF using endangered sturgeon species, Billard et al. 2004). Some of these rare or commercially important species have limited numbers of potential adult broodstock, so it is important to prove male fertility before potentially wasting ova with a male of unproven fertility. Measurement of DNA damage is one useful assay to check male broodstock fertility before running IVFs. The assessment of DNA damage in fish sperm for fertility assessment is so far achieved using the comet assay (Cabrita et al. 2005, Dietrich et al. 2005). The comet assay is consistent and able to determine singleor double-stranded breakage, and may also enable DNA sequence identification associated with DNA breaks (Fernández et al. 2001). However, the comet assay is technically challenging in requiring DNA electrophoresis and sophisticated image analysis software for achieving systematically consistent results. Such methods may be outside the abilities of many hatchery or aquarium facilities. We therefore conducted this study to assess the usefulness of the SCD test as a less technically demanding assay to measure SDF, and for the first time to understand the process in a teleost fish.

\section{Results \\ Dynamics of chromatin swelling}

Sperm head volume showed a significant increase from the start of activation (when diluted in freshwater) to 5 min after activation (ANOVA: $F_{1,98}=78, P<0.001$, $N=50$ sperm measured in either condition; Fig. 1).

\section{Sperm morphology following the SCD test}

A control treatment where sperm heads were embedded in the microgel at T0, but not subject to the SCD test, revealed a homogenous sperm morphology class represented by spherical sperm heads with minor differences in size (Fig. 2A). However, after applying the SCD test, the sperm sample could be grouped into two clear morphological classes: a) spherical sperm heads with or without small and compact haloes of chromatin dispersion (Fig. 2B identified by arrows and C and $\mathrm{D})$; and b) sperm heads of a variable size and showing highly dispersed haloes of spotted and dispersed chromatin, which expanded from a minimum chromatin core (Fig. 2B identified by arrowheads and $\mathrm{E}$ and $\mathrm{F}$ ). Within the sperm cell class producing compact haloes, two types could be discriminated: a) absence of halo of chromatin dispersion (identified by the vertical

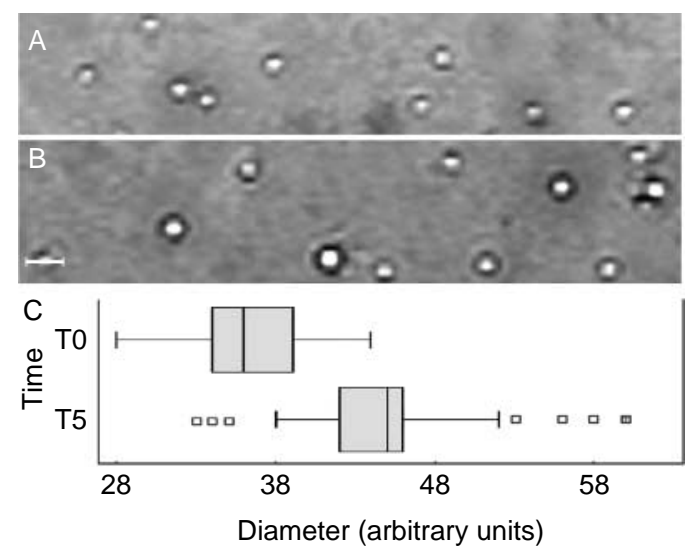

Figure 1 Chromatin swelling in tench sperm after being in contact with fresh water. (A) Sperm head sizes at the point of activation $(=\mathrm{T} 0$ $=$ time 0 ) and (B) $5 \mathrm{~min}$ after activation ( $=\mathrm{T} 5=$ time $5 \mathrm{~min}$ ). (C) Box and whisker plots show the distribution of the values for the diameter of each sperm cell, revealing an average increase of over $20 \% . N=50$ sperm measures at $T=0$ and 50 at $T=5$. Bar $20 \mu \mathrm{m}$. 


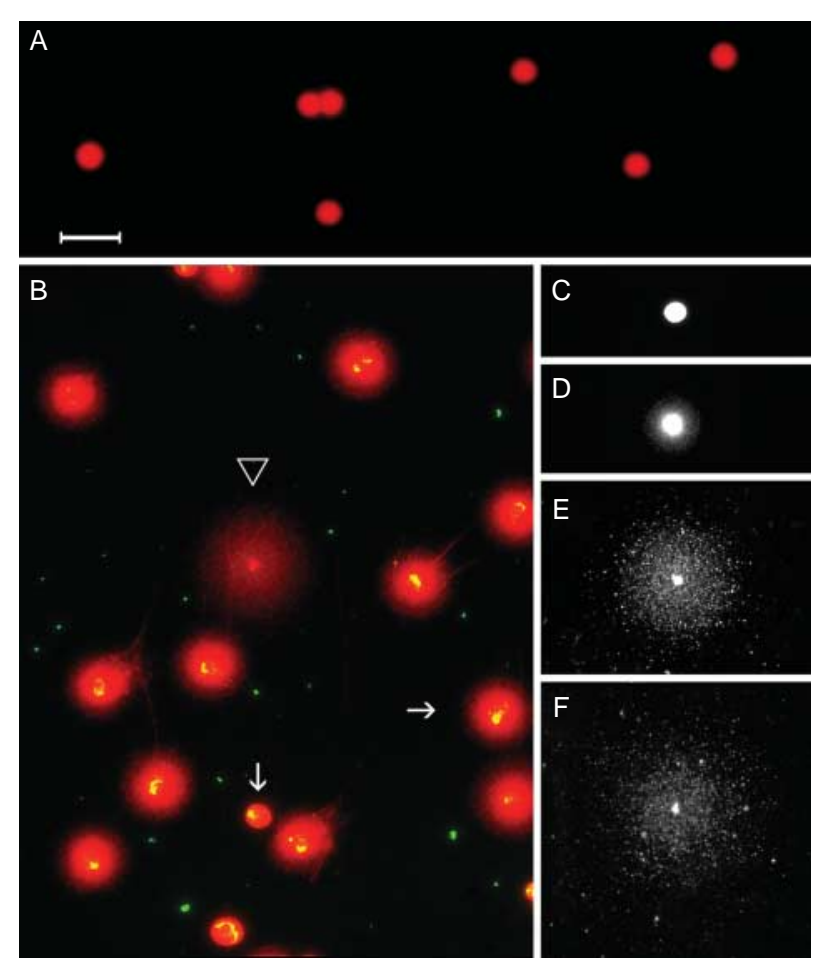

Figure 2 Chromatin morphology in control sperm cells (A) and after the SCD test $(B-F)$. Large and stellar haloes of chromatin dispersion represent cells with a high level of DNA damage (arrowhead in B). Additionally, small and compact haloes of chromatin dispersion (horizontal arrows in B) or nuclei containing undispersed chromatin (vertical arrow in B) were observed. From $C$ to $F$, a series of different sized and different levels of sperm DNA fragmentation. Note that the core density tends to diminish as DNA damage increases. Scale bar $=20 \mu \mathrm{m}$.

arrow in Fig. 2B and C) and b) a tighter halo around a compact core (identified by the horizontal arrow in Fig. 2B and C). In general, the stellar morphology of the sperm head core tends to diminish as the halo expands and the chromatin is dispersed: compare the series of images in Fig. 2C-F.

\section{In situ DNA labelling of DNA breakage}

To investigate whether the different morphology in the haloes was correlated with any possible presence of single- or double-stranded DNA breaks, we employed in situ labelling using ISNT for direct incorporation of labelled nucleotides in free $3^{\prime}$-OH termini resulting from both types of DNA breaks. After selective DNA labelling, all sperm cells showing haloes of chromatin dispersion, compact or stellar, were positively labelled (Fig. 3A, horizontal arrows and arrowheads). Nevertheless, the fluorescence intensity of the larger haloes formed by dispersed chromatin (arrowheads in Fig. 3) was 1.8 times greater $(992 \pm 161$ S.D., arbitrary units of fluorescence-integrated intensity) than that of the nuclei displaying more reduced halo of chromatin dispersion
$(511 \pm 93$ S.D. arbitrary units of fluorescence integrated intensity; horizontally arrowed nuclei in Fig. 3). After applying the colour lookup table (CLUT), it is clear that the dispersed chromatin out of the core shows the same colour code (blue in Fig. 3B), and therefore DNA labelling in the dispersed regions is similar. Those nuclei remaining compact, which do not exhibit any apparent halo of chromatin dispersion, also do not show labelling after ISNT, but remain with the red counterstain (Fig. 3, vertical arrow). Morphological differences in the haloes formed after chromatin dispersion and DNA labelling are much more evident after direct electronic image filtering is applied to enhance degrees of fluorescence (Fig. 3B).

\section{Testing the SCD test against the comet assay}

Because we detected an unexpectedly high level of cells with a small and compact halo (additional to cells where the halo was absent, or large and stellar) positive to ISNT, we conducted a further comparison using the comet
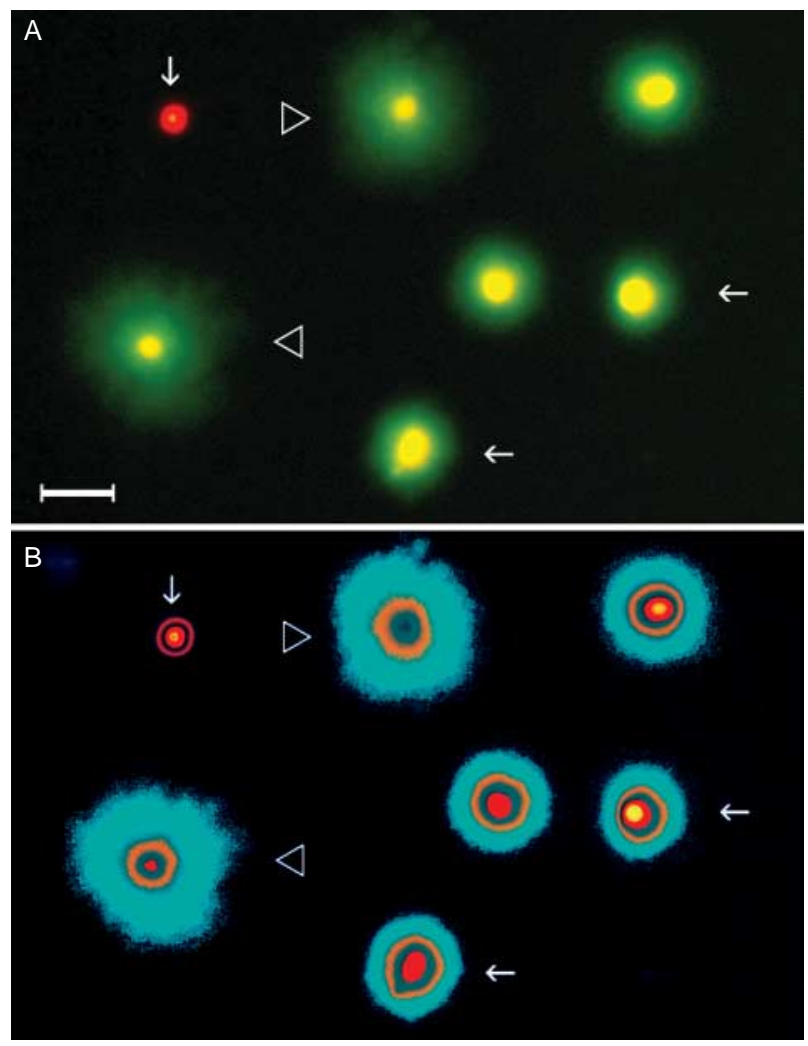

Figure 3 In situ nick translation to show the direct incorporation of labelled nucleotides (green signal) in sperm cells treated with the SCD. (A) Cells showing large haloes of chromatin dispersion are identified by arrowheads (stellar haloes) and the smaller haloes with horizontal arrows. Those with intact DNA are unlabelled and show red fluorescence counterstaining (vertical arrow). (B) Electronic filtered image to enhance these differences. Note a similar colour code (yellow red to blue) produced in the core and haloes according to the level of chromatin disorganization. Scale bar $=20 \mu \mathrm{m}$. 

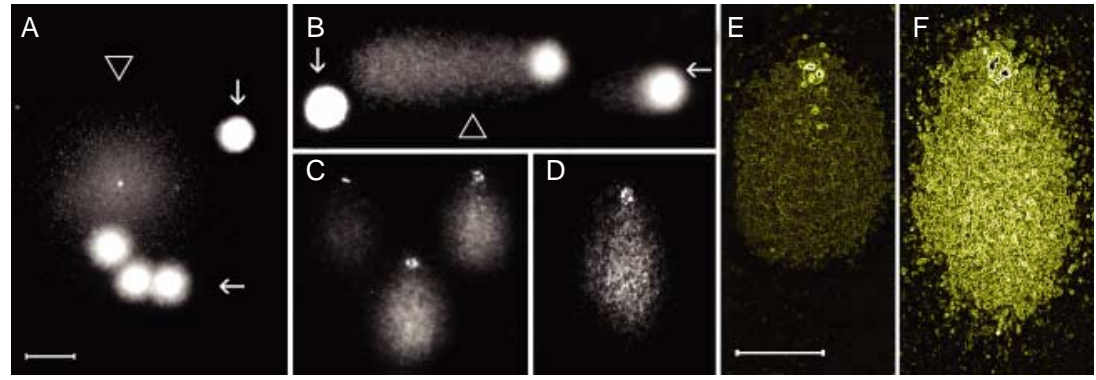

Figure $4 \mathrm{SCD}(\mathrm{A})$, neutral $(\mathrm{B})$ and alkaline $(\mathrm{C}$ and $\mathrm{D})$ comet assays in tench sperm at T0 immediately post-activation. Arrows in (A) follow the same code as in Fig. 2B. The neutral comet assay in (B) shows the three types of comet observed. The large comet is probably the stellar halo sperm cell observed after SCD (triangle in A). Horizontal arrow in (B) represents a nucleus with a low level of DNA damage that is probably not properly identified with the SCD. (C and D) Alkaline comet assay showing a group of sperm cells exhibiting a similar size for the comet - regular alkaline comet (C), while an irregular alkaline comet is depicted in (D-F). Electronic image filtering to enhance the chromatin differences in texture observed between regular and irregular alkaline comets (original images are top right comet of C and D). Scale bar $=20 \mu \mathrm{m}$.

assay to investigate whether differences in DNA breakage could result from single- or double-stranded breaks. This experiment was performed using sperm at time $=0$. We hypothesized that large and stellar haloes of chromatin dispersion (Fig. 4A arrowhead) corresponded to a higher level of DNA damage mostly represented by double-stranded DNA breaks, while single-stranded DNA breaks would be manifested by sperm with smaller haloes of dispersed chromatin (Fig. 4A, vertical and horizontal arrows).

When a neutral comet assay to localize doublestranded DNA breaks (Fig. 4B) was performed to compare the results with the SCD, we found a significant correlation across sperm samples from five males (nonparametric $R_{\mathrm{sp}}=0.9, P<0.05$; Fig. 5) when compared against the frequency of stellar haloes produced by the chromatin dispersion after the SCD. We therefore find concordance between these two methods for measuring DNA dispersion. In general, the neutral comet assay tended to produce slightly higher values in overall estimates of SDF than the SCD (Table 1); probably because the SCD test is slightly more conservative in revealing DNA dispersion compared with the neutral comet assay, as illustrated by the arrowed spermatozoa in Fig. 4B.

Interestingly, when an alkaline comet assay was used, a high proportion of the sperm cells produced a visible comet (Fig. 4C and Table 1). In general, the sizes of the migrant DNA loops were similar and gave rise to similarsized comet tails. The amount of DNA recovered in the tail after electrophoresis varies from one sperm to another (compare different comets in Fig. 4C). Additionally, in a variable and in a low proportion of sperm heads per individual, when compared to the regular alkaline comets (Table 1), the size of the tail produced under alkaline conditions was larger, i.e. the size of the migrant DNA loops was larger and the whole morphology of the comets was very distinctive to the previous class in terms of the chromatin morphology recovered (compare Fig. 4D with C). In fact, electronic filtering of images captured under identical conditions of exposure exhibits a very distinctive pattern of dispersed chromatin (compare Fig. 4E with F). This additional distinctive alkaline comet is interpreted as an additional presence of single-stranded DNA motifs produced after DNA denaturation. We refer to them as irregular alkaline comets (Table 1). Less than $2 \%$ of the sperm cells showed no evidence of DNA displacement because of the electrophoresis effect, revealing either small, undisplaced haloes, or no trace of halo at all; frequencies of these types are also summarized in Table 1.

\section{Repeatability and dynamics of SDF}

The results obtained for SDF using the SCD test showed direct concordance with the neutral comet assay. The SCD test is technically less demanding, so we tested the repeatability of the SCD test, and examined the

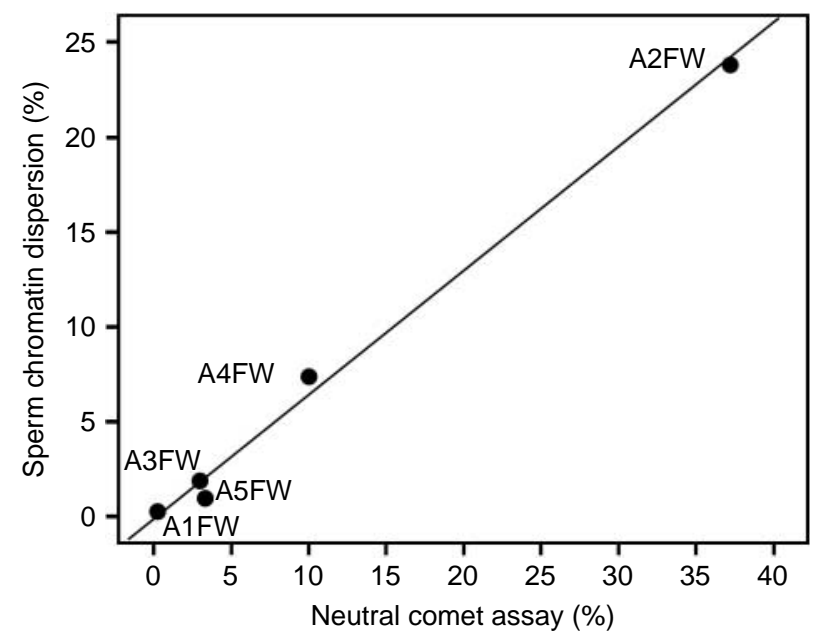

Figure 5 Correlation between two methods to measure \% DNA dispersion (Spearman rank correlation: $R=0.9$ ) across sperm expressed from five male fish and screened immediately post-activation using either the sperm chromatin dispersion test or the neutral comet assay. 
Table 1 Summary measures of DNA damage ( $\%$ of cells assayed) for five tench males at time 0 (on activation) after the sperm chromatin dispersion (SCD), neutral comet (NC) and alkaline comet (AC) assays. Regular alkaline comet $(\mathrm{rAC})$ corresponds to criteria identified in Fig. $4 \mathrm{C}$ and $\mathrm{D}$ and irregular alkaline ( $\mathrm{iAC}$ ) comet corresponds to criteria in Fig. 4D and E.

\begin{tabular}{lrrlll}
\hline & \multicolumn{5}{c}{ Sperm DNA fragmentation } \\
\cline { 2 - 6 } Male & SCD & NC & rAC & iAC & NC \\
\hline A1FW & 0.3 & 0.3 & 58.0 & 40 & 2 \\
A2FW & 22.0 & 34.0 & 36.0 & 63.6 & 0.4 \\
A3FW & 1.0 & 3.3 & 55.0 & 43.6 & 1.4 \\
A4FW & 7.3 & 10.0 & 63.0 & 35.6 & 1.6 \\
A5FW & 1.9 & 3.0 & 30.0 & 69.4 & 0.6 \\
\hline
\end{tabular}

dynamics of SDF for different males over time since sperm activation. By comparing the double-blind scores of 60 SCD tests for five fish from two independent observers, we were able to show that the SCD test has high repeatability (reliability analysis in SPSS 14.0 showed an intraclass correlation coefficient for average measures across 60 repeated measures $(N=2$ independent observers) $\left.R=0.996, F_{1,59}=11.39, P<0.001\right)$.

We measured how SDF changes over time since activation, and its variation between five male tench, averaging the (highly repeatable) measures for each fish at each time from two observers; results are plotted on Fig. 6. ANCOVA (using time since activation as a covariate) showed a significant difference between individual males in $\operatorname{SDF}\left(F_{4,54}=34.8, P<0.001\right)$ and significant covariance across increasing time $\left(F_{1,54}=293, P<0.001\right)$. In general, the males exhibited a low level of SDF, with values lower than $5 \%$ at sperm activation (time $=0$ ). However, one male (A2) exhibited elevated SDF with $20 \%$ of sperm showing damage at activation.

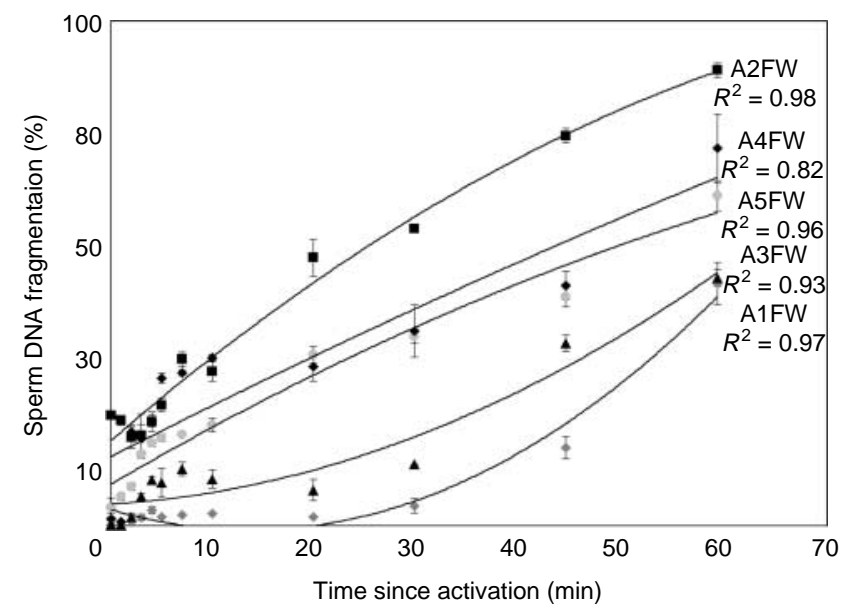

Figure 6 Consistent significant increases in the rate of sperm DNA fragmentation using the SCD test for five male tench. All $r^{2}=P<0.001$ and tested against second-order polynomial models; note that lines of best fit do not cross and there is between-male variance in SDF across time. Means (from $N=2$ observations at each time) plotted \pm s.D., 12 time measures per male.

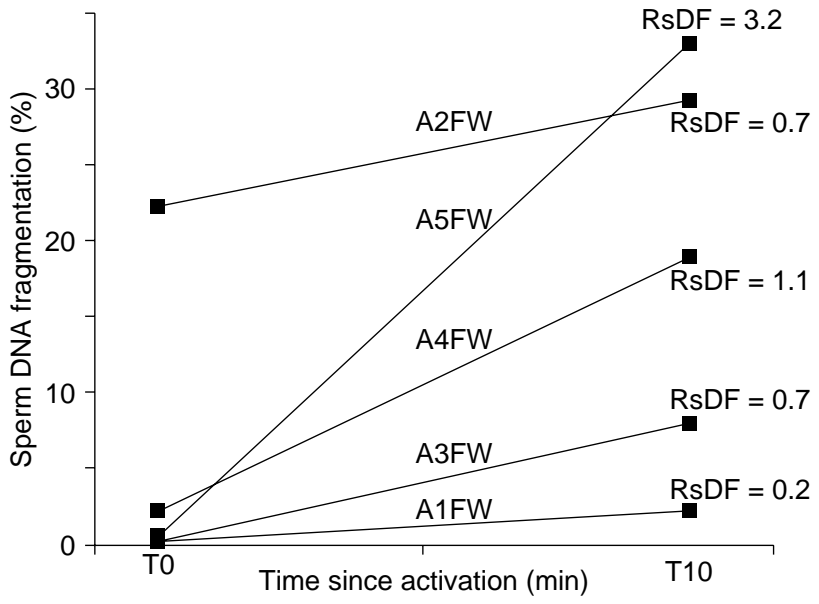

Figure 7 Rate of sperm DNA Fragmentation (RsDF) in the five analysed males over the first $10 \mathrm{~min}$ after capacitation, showing more variant short-term increases in RsDF between males (compared with Fig. 6).

All males showed significantly progressive increases in SDF over time since activation, so that at $60 \mathrm{~min}$ post-activation SDF was exhibited in $45-90 \%$ of all sperm screened (Fig. 6). The accumulation of SDF progressed at a similar rate for all males, so that males with initial low SDF also showed proportionally low sperm DNA damage at later times, as illustrated on Fig. 6 where individual male trend lines increased in parallel. Averaging across all males, we find that the rate of SDF in tench under our conditions increases at time $\times 0.883+8.39\left(R^{2}=0.96, P<0.001, N=12\right.$ average measures from five males between $T=0$ and $60 \mathrm{~min}$; see Fig. 6 for individual male trajectories).

Given that the rate of sperm DNA fragmentation (RsDF) in Tinca was very fast, and for some males increased in the first minutes after activation, we have also plotted the details of this relationship over the first 10 min of incubation after activation, and calculated the RsDF over the first 10 min after activation (Fig. 7).

\section{Discussion}

Our results demonstrate a correlation between the levels of stellar haloes of dispersed chromatin obtained with the SCD and SDF, measured using either ISNT (Fig. 3) or the neutral comet assay (Fig. 5). These results demonstrate that a part of the sperm DNA damage observed with the neutral comet or the SCD is congruent with the presence of double-stranded DNA damage. In addition, the small and compact haloes revealed by the SCD, and confirmed by the alkaline comet assay, demonstrate the widespread presence of non-orthodox DNA motifs that facilitate the production of single-stranded DNA motifs in the presence of alkali. These could be apurinic or apirimidinic sites (Liu et al. 2002) produced, in this case, by the effect of chromatin swelling occurring after activation. This would explain why, after ISNT, most of 
the cells (especially those exhibiting small and compact haloes) expressed the label after polymerase, since nucleotides are incorporated into the $3^{\prime}-\mathrm{HO}$ end following a single nick in the DNA. Accordingly, the SCD is not only a cost-effective and efficient assay for measuring DNA fragmentation in fish sperm, but also has the potential to distinguish between single- and doublestranded DNA breakages.

This possibility presents important consequences for a range of basic research into sperm DNA degradation, which remains poorly understood, even in humans (Tesarik et al. 2006, Ozmen et al. 2007). For example, the consequences of single- or double-stranded sperm DNA breakage for fertilization or embryogenesis remain unknown, although recognized as potentially important (Genescá et al. 1992, Khanna \& Jackson 2001, Zhang et al. 2007), and recognized in some recent studies (Gandini et al. 2004, Payne et al. 2005). In fish with external fertilization, artificial reproduction in hatcheries can result in embryo development problems and offspring malformations (Hauser \& Sissenwine 1991, Lough et al. 2008); we are now investigating relationships between DNA breakage and embryogenesis in fish. Interestingly, in mammalian species where this phenomenon has been more intensively investigated, high rates of SDF can still be associated with viable embryo production, suggesting repair mechanisms (Cho et al. 2003, Muriel et al. 2006, Collins et al. 2008). Further studies in fish and other taxa will determine how widespread such mechanisms of embryo DNA repair are.

One barrier to progress on SDF assessment is that available techniques to analyse sperm DNA damage are technically challenging to set up in many laboratories. This situation also tends to increase the rate of inconsistencies between laboratories. Our results show that the SCD technique is relatively simple, and we demonstrate that this assay shows tightly correlated measures with more complex techniques that depend on DNA electrophoresis, or apply DNA labelling using enzymatic incorporation of labelled nucleotides in putative DNA breaks or nicks (TUNEL or ISNT). Additionally, the SCD test provides the possibility for assessing the presence of single- or double-stranded DNA in a single experiment.

The haloes of chromatin dispersion with a stellar appearance revealed by the SCD test are those presenting double-stranded DNA damage, as confirmed by a correlation with the findings of the neutral comet assay. The other haloes exhibiting a more compact morphology are probably the result of dynamic chromatin swelling, which renders the DNA more susceptible to protein removal. This chromatin behaviour after protein depletion is similar to that described for other mammalian species (Gosálvez et al. 2006, Cortés-Gutierrez et al. 2008), but it is closer to the halo morphology exhibited by koala sperm after the SCD test (Johnston et al. 2007).
This phenomenon is probably due to the absence of $\mathrm{S}-\mathrm{S}$ bonds in the protamines in koalas (Fifis et al. 1990, Temple-Smith 1994), which could also apply to this fish species (Winkfein et al. 1993, Lewis et al. 2003). The tendency for halo formation here observed for Tinca sperm could be different in other species where the chromatin is arranged with $\mathrm{S}-\mathrm{S}$ bond forming amino acid residues. We have not investigated this aspect in detail here, but similar results were found in koalas where protein depletion was produced in the absence of dithiothreitol (DTT): a specific treatment to weaken disulphide bonds in protamines. Johnston et al. (2007) suggested a model of sperm chromatin organization in koalas where the tight organization of the sperm haploid genome required the distribution of non-orthodox DNA motifs, such as abasic sites or single-stranded DNA stretches, resident throughout the chromatin that allows specific sperm DNA packaging, but also show proclivity to be broken by processes such as freeze thawing and chromatin swelling (Johnston et al. 2006). Such sites may allow extreme compaction in the absence of $\mathrm{S}-\mathrm{S}$ bonding-mediated protamination, but also render the chromatin much more vulnerable to artificial stressors at these sites. This interpretation would explain why regular single-stranded DNA motifs, which produce similar length-tailed comets, are detected in sperm nuclei using the alkaline comet assay. In Tinca they seem to represent the response of a structural feature of chromatin exposed by external stressors such as osmotic pressure after sperm activation. Interestingly, the quick rate of chromatin swelling observed in Tinca is very similar to that shown by frozen semen samples of koala sperm after thawing (Johnston et al. 2006, Zee et al. 2008). This chromatin behaviour has never been reported in other mammalian species that contain capacity in their protamines for disulphide bonding. We therefore suggest that chromatin swelling, after activation of externally fertilizing fish sperm, is exposing chromatin regions more highly susceptible to alkaline denaturation, and subsequent protein lysis leads to single-stranded DNA breakage, probably related to the absence of $\mathrm{S}-\mathrm{S}$ bonds in the protamines.

Our results show that SDF needs to be measured and understood as an individual parameter of sperm quality, which behaves dynamically through time. We find that: a) DNA damage varies significantly between five male fish treated to similar experimental protocols, b) DNA damage increases at a predictable rate since activation in tench and c) that the damage at activation time is a good predictor of the extent of damage through time. In studies on humans and other mammalian species, it has been previously shown that DNA degrades when incubated in semen extenders at $37^{\circ} \mathrm{C}$ (Dalzell et al. 2004, Bungum et al. 2006, Gosálvez et al. 2007). This is of direct relevance because, for example, in routine human IVF, oocytes are exposed to sperm overnight with a maximum exposure to $20 \mathrm{~h}$. In some cases, this long period of 
co-incubation has produced fertilization and embryonic development problems (Dalzell et al. 2004), while good fertilization rates in IVF have been achieved with ultrashort co-incubation times (e.g. Bungum et al. 2006). The results we report here for tench show similar increases in SDF through time, and there will obviously be differences in species in this rate. In some species (such as human, stallion or ram), some individuals may double their basal level of SDF in only $5 \mathrm{~h}$, while in other species (such as boar and bulls) this effect is delayed even for some days (Perez-Llano et al. 2006, Gosálvez et al. 2007, 2008). Within this scenario, the rates of sperm DNA damage we report here for T. tinca are the fastest so far measured, possibly due to osmotic stress on the sperm cells after activation in freshwater, and or a slightly different chromatin structure without disulphide linkages in fish (Morisawa et al. 1983, Alavi \& Cosson 2006). We estimate that the RsDF after $10 \mathrm{~min}$ of activation is, on average, $1.2 \%$ per minute, although there is profound variation among different individuals (Fig. 7). According to our results, we would expect the lowest sperm quality to be that of individual A2FW, which demonstrates the highest basal level of SDF reaching almost $30 \%$ after $10 \mathrm{~min}$ of incubation. By contrast, individual A5FW demonstrates a low basal level of SDF, but that this increased to more than $30 \%$ after $10 \mathrm{~min}$ of incubation post-activation. According to these criteria, the best semen sample was produced by A1FW, which maintained a low level of SDF from activation up to $10 \mathrm{~min}$ of incubation. These individual references identify the between-male variability in both basal levels of SDF and in the dynamics of SDF through time. Further work exploring SDF within buffered media and extenders could determine the importance of osmotic stress for DNA damage.

Using these techniques to analyse SDF, the RsDF, expressed in minutes, would be almost unappreciable for other mammals. Thus, in human, for example, the RsDF would be around $2 \%$ per hour in fertile donors' samples that were frozen thawed (Gosálvez et al. 2009a), while in ram, where sperm is more intensely affected by external stressors, the RsDF for chilled semen samples is on the order of $2.4 \%$ per hour, and rates increased after freeze thawing to values of $9.3 \%$ per hour (López-Fernández et al. 2008). This variation demonstrates wide variability between species in sensitivity to DNA damage, and here for fish demonstrates a potentially rapid decay in DNA quality of consideration for aquaculture. Our results are directly relevant for assisted reproduction technologies in tench and other fishes: a) since DNA damage increases with time, it is important to get sperm into contact with ova as soon as possible and $\mathrm{b}$ ) there is wide variation between males in the extent of DNA damage, so that some males could generate poor fertilities, especially if delays in fertilization after stripping occur. For example, one of our five males demonstrated $20 \%$ basal DNA damage before activation, potentially rendering it unsuitable as broodstock. The inter-individual variation in the rate of DNA damage at a relevant time since ejaculation could be a useful measure for pre-screening males before selection for artificial insemination, especially when ova are limited or expensive.

In summary, the SCD test we describe presents clear opportunities for rapidly pre-screening males to be used in assisted reproduction technology, since we know for other taxa that increased SCD correlates with compromised male fertility. To optimize the methods for fish, we are now assessing SDF between strips of individual males, and measuring the relationships between a) SCD and male fertility (under single and competing ejaculate conditions), b) SCD and embryonic development and c) SCD under the influence of sperm extenders.

\section{Materials and Methods}

\section{Sperm recovery}

Five males of T. tinca (Teleostei, Cyprinidae) in breeding condition (internal reference: A1FW, A2FW, A3FW, A4FW and A5FW: FW, fresh water) were randomly collected from the stock maintained in semi-captivity in the hatchery Tencas de Casaseca (Zamora, Spain). Milt was gently expressed from each male using standard hatchery stripping techniques. Briefly, each male was inverted, and then gentle abdominal pressure was applied by hand from the anterior to the posterior of the fish. Care was taken to only collect milt, avoiding contamination by water, urine or mucus. Within 1 min of stripping, the milt was activated in fresh-filtered river water at a concentration of $1 \mathrm{ml}$ milt: $200000 \mathrm{ml}$ water and the SCD test performed. We separately analysed two aliquots for each of the five activated ejaculates for SCD to measure within-male and between-male variation. To measure the dynamics of SDF over time, we performed the same assays at 11 further times after activation (T1, 2, 3, 4, 5, 7, 10, 20, 30, 45 and $60 \mathrm{~min}$ ) at a controlled temperature of $15{ }^{\circ} \mathrm{C}$. T0 was considered as the basal level of SDF for each animal and the assessment was performed as soon as the sperm was activated. To express the 'velocity' of sperm DNA damage, we introduced the acronym RsDF to represent the rate of sperm DNA Fragmentation as the increasing proportion of damaged spermatozoa per minute.

\section{SCD test}

The SCD test to assess SDF in Tinca was adapted by ChromaCell SL (ChromaCell SL, Madrid, Spain), and a prototype kit (Halomax Proto-Tinca) was developed using the following methods. Gelled aliquots $(50 \mathrm{ml})$ of low melting point agarose in Eppendorf tubes $(1 \%$ agarose provided in the kit) were placed in a water bath at $90-100{ }^{\circ} \mathrm{C}$ for 5 min to melt the agarose. The temperature was then equilibrated to $30^{\circ} \mathrm{C}$ for $5 \mathrm{~min}$ in a water bath prior to the addition of the sperm sample. Twenty-five microlitres of activated sperm in filtered river water were added to the low melting agarose and gently mixed. The final concentration, to obtain a suitable sperm dispersion on microscope slides for assessment, was $\sim 10$ million sperm $/ \mathrm{ml}$. 
The low melting agarose containing the spermatozoa was then pipetted onto a pre-treated slide provided in the Halomax kit, and then covered with a $22 \times 22 \mathrm{~mm}$ coverslip. The slide was then placed on a cold metal plate (at $4{ }^{\circ} \mathrm{C}$ ) in the refrigerator for $5 \mathrm{~min}$ to allow the agarose to set into a thin microgel. The coverslip was then gently removed, and the slide treated with lysing solution containing $2 \mathrm{M} \mathrm{NaCl}, 0.5 \%$ SDS, 0.01 Triton $\mathrm{X}$, $0.2 \mathrm{M}$ Tris- $\mathrm{HCl}$ and $0.02 \mathrm{M}$ EDTA, $\mathrm{pH} 7$ (provided in the kit) for $5 \mathrm{~min}$. Following lysis, the slide was washed in distilled water for further $5 \mathrm{~min}$, and then dehydrated in an increasing series of ethanol baths (70, 90 and 100\%) for 2 min each and finally airdried. In order to differentiate possible somatic cell contamination from sperm cells, we ran a double-staining protocol using a $0.5 \times$ GelRed for DNA (Biotium, Hayward, CA, USA) in distilled water, counterstained with $0.05 \mu \mathrm{g} / \mathrm{ml}$ of 2,7-dibromo4-(hydroxymercuri)-fluorescein disodium salt (Sigma-Aldrich) for protein thiols, and disulphide staining (Nöhammer \& Desoye 1997). Because fish sperm DNA contains no cysteine residues, Vectashield mounting medium H-1000 (Vector Laboratories, Burlingame, CA, USA) was used to reduce fading of fluorescence. The dual-emission fluorochrome combination allowed simultaneous visualization of DNA and total proteins (red for DNA and green for proteins) using a dual-band pass fluorescence filter block; alternatively, single-emission fluorescence could be observed using a single-band pass fluorescence filter block. Sperm were observed using a Leica DMRB (Leica Microsystems, Wetzlar, Germany) epifluorescence microscope using $40 \times$ or $60 \times$ magnification lenses, and images captured via a cooled Photometrics (Roper Industries, Inc., Duluth, GA, USA) CCD for direct colour 16-bit captures, and a CCD DFC-350-FX Leica for 8-bit grey-level imaging.

\section{Chromatin swelling, ISNT and comet assay}

To correlate the SCD test with other protocols, we employed measures of chromatin swelling, ISNT and the comet assay to visualize sperm DNA changes and breakage. The dynamics of chromatin swelling were recorded through a series of video recordings captured from the start of sperm activation to $5 \mathrm{~min}$. Video sequences were recorded using a Motic BA300 brightfield microscope equipped with a CCD Moticam 2000 (Motic, Barcelona, Spain) under $600 \times$ magnification using phasecontrast microscopy. Single images were captured from video sequence and measured using Motic image analysis software. The head diameter of 50 different sperm cells was measured for each male at the point of activation (within $1 \mathrm{~min}$ ) and at $5 \mathrm{~min}$ from activation.

For ISNT, slides after lysis were directly processed without any dehydration steps. Slides were thoroughly washed four times in PBS for $5 \mathrm{~min}$, and then incubated four times for $5 \mathrm{~min}$ in excess reaction buffer for DNA polymerase I $(10 \mathrm{mM}$ Tris$\mathrm{HCl}, 5 \mathrm{mM} \mathrm{MgCl}_{2}$ and $7.5 \mathrm{mM}$ DTT, pH 7.5). Then, $100 \mu \mathrm{l}$ of reaction buffer containing 25 units of DNA polymerase I (New England BioLabs, Beverly, MA, USA) and biotin-16-dUTP in the nucleotide mix were pipetted onto the slide, covered with a plastic coverslip and incubated in a moist chamber for $30 \mathrm{~min}$ at $37^{\circ} \mathrm{C}$. After washing in $89 \mathrm{mM}$ Tris, $89 \mathrm{mM}$ boric acid and $2.5 \mathrm{mM}$ EDTA, pH 8.3 (TBE) buffer, the slides were then dehydrated in sequential $70-90-100 \%$ ethanol baths and air-dried. The incorporated biotin-16-dUTP was detected by incubation with the appropriate antibody conjugated with FITC for $30 \mathrm{~min}$. The slides could be directly analysed or counterstained with propidium iodide $(2 \mu \mathrm{g} / \mathrm{ml})$ in Vectashield. As a control, an area of the slide was incubated with the reaction buffer alone, omitting the DNA polymerase I. The microgel between the areas with and without the polymerase was scratched away to avoid possible diffusion of the enzyme into the control area.

DNA damage was also assessed using both neutral comet assays for double-stranded DNA breakage analysis, and alkaline comet assays to assess single-stranded DNA breaks. The alkaline comet assay was performed according to Singh et al. (1989). Sperm-gel slides were prepared as described previously for the SCD test. The slides were immersed in two lysis solutions: $0.4 \mathrm{M}$ Tris- $\mathrm{HCl}(\mathrm{pH} 7.5), 0.8 \mathrm{M} \mathrm{DTT}, 1 \%$ SDS or

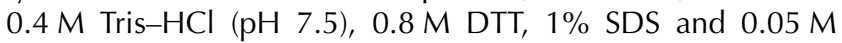
EDTA for $30 \mathrm{~min}$ each, at room temperature. The slides were washed in TBE buffer for $10 \mathrm{~min}$ and then treated with fresh alkaline solution $(0.03 \mathrm{M} \mathrm{NaOH}$ and $1 \mathrm{M} \mathrm{NaCl})$ for $2.5 \mathrm{~min}$ to cleave the alkali-labile sites. The slides were placed horizontally in an electrophoresis tray, which was filled with fresh alkaline electrophoresis solution (0.03 $\mathrm{M} \mathrm{NaOH}, \mathrm{pH} 13)$. Electrophoresis was conducted at $20 \mathrm{~V}$ for $20 \mathrm{~min}$ at room temperature. After electrophoresis, the slides were gently removed from the tray and washed with neutralizing buffer (0.4 M Tris- $\mathrm{HCl}, \mathrm{pH}$ 7.5) for $5 \mathrm{~min}$. The slides were washed in distilled water for $5 \mathrm{~min}$, and then dehydrated in a sequential series of 70, 90 and $100 \%$ ethanol. For the neutral comet assay, the slides were treated with the lysis solutions described above and electrophoresis was performed in neutral buffer $(1 \mu \mathrm{ITBE})$ at $20 \mathrm{~V}$ for $20 \mathrm{~min}$. Finally, the slides were stained with propidium iodide $(20 \mu \mathrm{g} / \mathrm{ml})$ and visualized under a fluorescence microscope. At least 100 cells per experiment were analysed at $600 \times$ magnification.

\section{Image analysis}

Image manipulation was performed with Adobe Photoshop 7.0 (Adobe Systems Incorporated). Colour image construction using grey-level images was performed using channel assignation merging within Adobe Photoshop. The original grey-scale images were electronically filtered to construct an enhanced RGB file. This filtering allows further detail in the degree of DNA damage to be assessed. Merged grey-scale images are converted to RGB files (with no information in B) maintaining the information as captured by the CCD. Using Adobe Photoshop, a CLUT based on a curve transformation of the original linear RGB information was performed. In image analysis, a CLUT is a mechanism used to transform a range of input colours into another range of colours for image enhancement. In our case, two points were fixed within the linear information (at 70 and 170 RGB values) to redistribute the original values. The original value of 70 is transformed to IN values of 60 and OUT values of 200, while the 170 value is transformed into IN 200 and OUT 70. Once the threshold values are fixed, different images captured under the same conditions could be pseudo-coloured under the same criteria. This filter was applied to images that were all captured with 
identical exposure times, generating a redistribution of the grey-scale information in which the variation between sperm DNA haloes with varying degrees of fragmentation is notably highlighted, allowing further discrimination within the regions of interest (compare Fig. 3A with B). Pseudo-colour filtering allows quantified grouping of the different levels of chromatin dispersion by a colour code (Fig. 3B). All statistical analyses were conducted using SPSS version 14.0 for Windows. Parametric tests were applied (ANOVA, ANCOVA and regression) apart from one case where data deviated from a normal distribution, and so a non-parametric Spearman rank correlation was employed.

\section{Declaration of interest}

The authors declare that there is no conflict of interest that could be perceived as prejudicing the impartiality of the research reported.

\section{Funding}

Our research was supported by grants BFU 2007-66340/BFI and CCG06-UAM/AGR-0307.

\section{Acknowledgements}

We acknowledge Prof Godfrey M Hewitt who facilitated this research collaboration between the UAM and UEA research teams. The authors would like to acknowledge ChromaCell SL for technical support. Work supported by grants BFU 200766340/BFI and CCG06-UAM/AGR-0307.

\section{References}

Alavi SMH \& Cosson J 2006 Sperm motility in fishes. (II) Effects of ions and osmolality: a review. Cell Biology International 30 1-14.

Billard R, Cosson J, Noveiri SB \& Pourkazemi M 2004 Cryopreservation and short-term storage of sturgeon sperm a review. Aquaculture 236 1-9.

Braun RE 2001 Packaging paternal chromosomes with protamine. Nature Genetics 28 10-12.

Bungum M, Bungum L \& Humaidan P 2006 A prospective study using sibling oocytes examining the effect of 30 seconds versus 90 minutes gamete co-incubation in IVF. Human Reproduction 21 518-523.

Cabrita E, Robles V, Rebordinos L, Sarasquete C \& Herráez MP 2005 Evaluation of DNA damage in rainbow trout (Oncorhynchus mykiss) and gilthead sea bream (Sparus aurata) cryopreserved sperm. Cryobiology $\mathbf{5 0}$ 144-153.

Cho C, Jung-Ha H, Willis WD, Goulding EH, Stein P, Xu Z, Schultz RM, Hecht NB \& Eddy EM 2003 Protamine 2 deficiency leads to sperm DNA damage and embryo death in mice. Biology of Reproduction 69 211-217.

Collins JA, Barnhart KT \& Schlegel PN 2008 Do sperm DNA integrity tests predict pregnancy with in vitro fertilization? Fertility and Sterility $\mathbf{8 9}$ 823-831.

Cortés-Gutierrez E, Crespo F, Gosálbez A, Dávila-Rodriguez M, LópezFernández C \& Gosálvez J 2008 DNA fragmentation in frozen sperm of Equus asinus: Zamorano-Leonés a breed at risk of extinction. Theriogenology 69 1022-1032.

Dalzell LH, McVicar CM, McClure N, Lutton D \& Lewis SE 2004 Effects of short and long incubations on DNA fragmentation of testicular sperm. Fertility and Sterility 82 1443-1445.
Dietrich GJ, Szpyrka A, Wojtczak M, Dobosz S, Goryczkoc K, Żakowskic Ł \& Ciereszko A 2005 Effects of UV irradiation and hydrogen peroxide on DNA fragmentation motility and fertilizing ability of rainbow trout (Oncorhynchus mykiss) spermatozoa. Theriogenology 64 1809-1822.

Evenson D \& Wixon R 2006 Meta-analysis of sperm DNA fragmentation using the sperm chromatin structure assay. Reproductive Biomedicine Online 12 466-472.

Fernández JL, Vázquez-Gundín F, Rivero MT, Genescá A, Gosálvez J \& Goyanes V 2001 DBD-fish on neutral comets: simultaneous analysis of DNA single- and double-strand breaks in individual cells. Experimental Cell Research 270 102-109.

Fernández JL, Muriel L, Rivero MT, Goyanes V, Vázquez R \& Alvarez J 2003 The sperm chromatin dispersion test: a simple method for the determination of sperm DNA fragmentation. Journal of Andrology 24 59-66.

Fifis T, Cooper DW \& Hill RJ 1990 Characterization of the protamines of the Tammar wallaby (Macropus eugenii). Comparative Biochemistry and Physiology. Part B, Biochemistry and Molecular Biology 95 571-575.

Gandini L, Lombardo F, Paoli D, Caruso F, Eleuteri P, Leter G, Ciriminna R, Culasso F, Dondero F, Lenzi A et al. 2004 Full-term pregnancies achieved with ICSI despite high levels of sperm chromatin damage. Human Reproduction 19 1409-1417.

Genescá A, Caballín MR, Miró R, Benet J, Germa JR \& Egozcue J 1992 Repair of human sperm chromosome aberrations in the hamster egg. Human Genetics 82 181-186.

Gorczyca W, Traganos F, Jesionowska H \& Darzynkiewicz Z 1993 Presence of DNA strand breaks and increased sensitivity of DNA in situ to denaturation in abnormal human sperm cells: analogy to apoptosis of somatic cells. Experimental Cell Research 207 202-205.

Gosálvez J, Fernández JL, Goyanes V \& López-Fernández C 2006 Análisis de la fragmentación del ADN en espermatozoides mediante el test de dispersión de la cromatina (SCD). Biotechnology $138-51$.

Gosálvez J, Fernández JL, Gosálbez A, Arrollo F, Agarwal A \& LópezFernández C 2007 The dynamics of sperm DNA fragmentation in mammalian species as assessed by the SCD methodology. Fertility and Sterility 88 S365.

Gosálvez J, Cortés-Gutierrez El, López-Fernández C, Fernández JL, Caballero P \& Núñez R 2009a Sperm deoxyribonucleic acid fragmentation dynamics in fertile donors. Fertility and Sterility 92 170-173.

Gosálvez J, Cortés-Gutierrez EI, Núñez R, Fernández JL, Caballero P, López-Fernández C \& Holt WV 2009b A dynamic assessment of sperm DNA fragmentation versus sperm viability in proven fertile human donors. Fertility and Sterility [in press]. DOI: 10.1016/j.fertnstert.2008. 08.136 .

Gosálvez J, Núñez R, Caballero P, Fernández JL, Cortés-Gutiérrez El \& López-Fernández C 2008 Fragmentación del ADN espermático ¿un concepto dinámico o estático? Revista Iberoamericana de Fertilidad y Reproducción Humana 25 195-206.

Hauser JW \& Sissenwine MP 1991 The uncertainty in estimates of the production of larval fish derived from samples of larval abundance. ICES Journal of Marine Science 48 23-32.

Hoysak DJ \& Liley NR 2001 Fertilization dynamics in sockeye salmon and a comparison of sperm from alternative male phenotypes. Journal of Fish Biology 58 1286-1300.

Johnston SD, MacCallum C, Blyde D, McClean R, Lisle A \& Holt WV 2006 An investigation into the similarities and differences governing the cryopreservation success of koala (Phascolarctos cinereus: Goldfuss) and wombat (Vombatus ursinus: Shaw) spermatozoa. Cryobiology 53 218-228.

Johnston SD, López-Fernández C, Gosálbez A, Zee YP, Holt WV, Allen C \& Gosálvez J 2007 The relationship between sperm morphology and chromatin integrity in the koala (Phascolarctos cinereus) as assessed by the sperm chromatin dispersion (SCD) test. Journal of Andrology $\mathbf{2 8}$ 891-899.

Khanna KK \& Jackson SP 2001 DNA double strand breaks: signaling repair and the cancer conection. Nature Genetics 27 247-254.

Lewis JD, Song Y, de Jong ME, Bagha SM \& Ausió J 2003 A walk though vertebrate and invertebrate protamines. Chromosoma 111 473-482.

Liu PK, Cui J, Moore N \& Huang D 2002 The in situ detection of apurinic/apyrimidinic sites and DNA breaks bearing extension blocking termini. Methods in Molecular Biology 203 235-244. 
López-Fernández C, Crespo F, Arroyo F, Fernández JL, Arana P, Johnston SD \& Gosálvez J 2007 Dynamics of sperm DNA fragmentation in domestic animals II: the stallion. Theriogenology 68 1240-1250.

López-Fernández C, Fernández JL, Gosálbez A, Arroyo F, Vázquez JM, Holt WV \& Gosálvez J 2008 Dynamics of sperm DNA fragmentation in domestic animals III Ram. Theriogenology 70 898-908.

Lough R, O'Brien GL \& Buckley LJ 2008 Differential egg mortality of Georges Bank cod and haddock inferred from two independent estimates of seasonal egg production. Journal of Northwest Atlantic Fishery Science 41 119-128.

Marchesi DM \& Feng HL 2007 Sperm DNA integrity from sperm to egg. Journal of Andrology 28 481-489.

Morisawa M, Suzuki K, Shimizu H, Morisawa S \& Yasuda K 1983 Effects of osmolality and potassium on motility of spermatozoa from freshwater cyprinid fishes. Journal of Experimental Biology 107 95-103.

Morris ID, Ilott S, Dixon L \& Brison DR 2002 The spectrum of DNA damage in human sperm assessed by single cell gel electrophoresis (Comet assay) and its relationship to fertilization and embryo development. Human Reproduction 17 990-998.

Muriel L, Garrido N, Fernández JL, Remohi J, Pellicer A, de los Santos MJ \& Merseguer M 2006 Value of the sperm deoxyribonucleic acid fragmentation level as measured by the sperm chromatin dispersion test in the outcome of in vitro fertilization and intracytoplasmic sperm injection. Fertility and Sterility 85 371-383.

Nöhammer G \& Desoye G 1997 Mercurochrom can be used for the histochemical demonstration and microphotometric quantitation of both protein thiols and protein (mixed) disulfides. Histochemistry and Cell Biology 107 383-390.

Ozmen B, Koutlaki N, Youssry M, Diedrich K \& Al-Hasani S 2007 DNA damage of human spermatozoa in assisted reproduction: origins diagnosis impacts and safety. Reproductive Biomedicine Online 14 384-395.

Payne JF, Raburn DJ, Couchman GM, Price TM, Jamison MG \& Walmer DK 2005 Redefining the relationship between sperm deoxyribonucleic acid fragmentation as measured by the sperm chromatin structure assay and outcomes of assisted reproductive techniques. Fertility and Sterility $\mathbf{8 4}$ 356-364.

Pérez-Llano B, Enciso M, García-Casado P, Sala R \& Gosálvez J 2006 Sperm DNA fragmentation in boars is delayed or abolished by using sperm extenders. Theriogenology 66 2137-2143.
Singh NP, Danner DB, Tice RR, McCoy MT, Collins GD \& Schneider EL 1989 Abundant alkali-sensitive sites in DNA of human and mouse sperm. Experimental Cell Research 184 461-470.

Stockley P, Gage MJG, Parker GA \& Moller AP 1997 Sperm competition in fishes: the evolution of testis size and ejaculate characteristics. American Naturalist 149 933-954.

Temple-Smith PD 1994 Comparative structure and function of marsupial spermatozoa. Reproduction, Fertility, and Development 6 421-435.

Tesarik J, Mendoza-Tesarik R \& Mendoza C 2006 Sperm nuclear damage: update on the mechanism diagnosis and treatment. Reproductive Biomedicine Online 12 715-721.

Tice RR, Agurell E, Anderson D, Burlinson B, Hartmann A, Kobayashi H, Miyamae Y, Rojas E, Ryu JC \& Sasaki YF 2000 Single cell gel/comet assay: guidelines for in vitro in vivo genetic toxicology testing. Environmental and Molecular Mutagenesis 35 206-221.

Ward WS \& Coffey DS 1991 DNA packaging and organization in mammalian spermatozoa: comparison with somatic cells. Biology of Reproduction 44 569-574.

Winkfein RJ, Nishikawa S, Connor W \& Dixon GH 1993 Characterization of a marsupial sperm protamine gene and its transcripts from the North American opossum (Didelphis marsupialis). European Journal of Biochemistry 215 63-72.

Yeates S, Searle J, Ward RG \& Gage MJG 2007 A two-second delay confers first-male fertilization precedence within in vitro sperm competition experiments in Atlantic salmon. Journal of Fish Biology 70 318-322.

Zee YP, Holt WV, Gosálvez J, Allen CD, Nicolson V, Pyne M, Burridge M, Carrick FN \& Johnston SD 2008 Dimethylacetamide can be used as an alternative to glycerol for the successful cryopreservation of koala (Phascolarctos cinereus) spermatozoa. Reproduction, Fertility, and Development 20 1-10.

Zhang X, San Gabriel M, Libman J, Phillips S, Courchesne A \& Zini A 2007 Localization of single-stranded DNA in human sperm nuclei. Fertility and Sterility 88 1335-1338.

Received 18 March 2009

First decision 12 May 2009

Revised manuscript received 26 May 2009

Accepted 3 June 2009 